Case Study

\title{
An assessment of a very severe cyclonic storm in the Arabian sea using the COSMO model
}

\author{
Roshny S. ${ }^{1,2}$. D. Bala Subrahamanyam ${ }^{1}\left[\right.$ ] Anurose T. J. ${ }^{3} \cdot$ Radhika Ramachandran $^{1}$
}

Received: 20 June 2020 / Accepted: 7 October 2020 / Published online: 23 October 2020

(c) Springer Nature Switzerland AG 2020

\begin{abstract}
Accurate and reliable representation of convective processes is one of the major sources of uncertainty in numerical weather prediction (NWP) models, especially for those operating in the grey zone resolutions. The performance of NWP models become more sensitive to their grid resolutions, when they are used for simulation of severe weather events, such as a cyclonic storm. In this paper, we present a detailed assessment of an intense convective episode with heavy precipitation associated with the passage of a very severe cyclonic storm "OCKHI" using the Consortium for Small-scale Modelling (COSMO). A set of distinct numerical simulations are carried out using COSMO to address the impact of grid resolution and the treatment of explicit and implicit convection. Results obtained from the present investigation indicate that explicit treatment of convection in the COSMO model led to improved prediction of the cyclonic event in terms of sea level pressure, maximum sustained surface wind speeds and the accumulated rainfall, but reduction of the spatial grid resolution from 7 to $3 \mathrm{~km}$ did not show appreciable differences in the forecast fields. Conclusively, the current study recommends switching off the convection parameterization scheme at a grid resolution of $7 \mathrm{~km}$ for improved predictability of tropical cyclones.
\end{abstract}

Keywords COSMO $\cdot$ Tropical cyclone $\cdot$ Convection $\cdot$ Precipitation $\cdot \mathrm{OCKHI} \cdot$ Parameterization of convection

\section{Introduction}

Advances in numerical weather prediction (NWP) models is directly linked with the dramatic increase in processing powers of supercomputers which has enabled numerical simulations of the atmosphere at very fine grid spacing in a range as small as 1-10 km [1]. At such resolutions, the physical processes such as turbulence, convective transport and clouds can be partially resolved, which are otherwise represented through parameterization schemes at coarser resolutions [2]. Presently, there is still no agreement in mainstream researchers on whether a convection parameterization is obligatory at "gray-zone" resolutions as the small grid boxes in the NWP models are still inadequate to represent the complete spectrum of convective motions [3-6]. Moreover, convection involves complex interactions with cloud formation which influence the atmospheric circulation through diabatic and radiative effects. Methods for simulating convective precipitation have been a major focus during the evolution of

Electronic supplementary material The online version of this article (https://doi.org/10.1007/s42452-020-03645-7) contains supplementary material, which is available to authorized users.

D. Bala Subrahamanyam, subrahamanyam@gmail.com; Roshny S., roshnyjagan@gmail.com; Anurose T. J., anurostj@gmail.com; Radhika Ramachandran, 601 sree@gmail.com | 'Space Physics Laboratory, Vikram Sarabhai Space Centre, Department of Space, Government of India, Indian Space Research Organisation, Thiruvananthapuram 695 022, Kerala, India. ${ }^{2}$ Cochin University of Science and Technology, Cochin 682 022, Kerala, India. ${ }^{3}$ National Centre for Medium Range Weather Forecasting, Ministry of Earth Sciences, Government of India, Noida 201 301, Uttar Pradesh, India. 
NWP models over the past few decades. Notwithstanding, the advancement toward this path has been moderately delayed because of numerous ambiguities in both representing the problem as well as modelling the complex processes in convective events [7]. Furthermore, the schemes of parameterization in a model are directly or indirectly linked with each other, and reducing the errors attributed to one scheme needs improvements across the board to all facets of the model $[8,9]$.

Refinement in spatial grid resolution of the weather prediction models is constrained by the advancement in computational infrastructure. Currently, most of the regional operational NWP models are configured for a spatial grid resolution of a few kilometers. The initial conditions and time-varying lateral boundary conditions for the regional NWP models are obtained by downscaling the coarse-grid data from the global models after taking into account of the distinct features of the surface and model topography, which are generally available at far better spatial resolutions. Even though the larger scale forecasts contain the downscaled product, the process of downscaling may still add considerable value in certain circumstances, like when an intense convective event prevails over the study domain [10]. At very fine grid resolution, the model attains inherent potential to explicitly resolve these processes. In this manner, dynamical downscaling of NWP models provide cloud-resolving capabilities, and the parameterization of convective processes tends to become an obsolete component within the regional high-resolution simulations. However, there is still lack of agreement within the NWP community on this topic, and scientific debate is going on regarding: (1) how the parameterization of convection can be "switched off" at fine grid resolution? [11]; and (2) at which spatial grid resolution such a toggle must take place in NWP models? The onus is on obtaining a balance with a sufficiently high resolution which realistically represents convective processes and precipitation statistics without using a convection parameterization scheme, within the capabilities of the available computer resources. Ultimately, the modellers would like to have a scale-aware parameterization scheme, so that it turns off naturally at fine grid resolution.

The tropical cyclones (TCs) have the potential to be disastrous weather phenomena and are capable of causing substantial damage to life and physical infrastructure in tropical maritime countries [12]. Extreme winds and heavy rainfall associated with TCs have drawn the attention of researchers over the years, and fine-grid NWP forecasts have been helping the decision-makers to take advance precautions towards the passage of TCs. Accuracy of an operational NWP model in terms of early prediction of a TC, its movement, intensity, and associated precipitation is invariably linked with the performance of different parameterization schemes adopted by the model for treatment of subgrid-scale processes. Here we present a case study on the treatment of convection in a regional NWP model, namely-Consortium for Small-scale Modelling (COSMO) during the passage of OCKHI, a "Very Severe Cyclonic Storm (VSCS)" over the central Arabian sea. OCKHI was one of the rarest cyclonic storms whose genesis took place in the Comorin Sea and subsequently the storm traveled more than $2000 \mathrm{~km}$ over the Arabian sea before making its landfall on the western coastline of the Indian peninsula. OCKHI attained rapid intensification from a deep depression over the Comorin sea to a cyclonic storm within $6 \mathrm{~h}$ itself $[13,14]$.

The main objectives are broadly categorized into two aspects: (1) To study impact of downscaling on different atmospheric fields including the precipitation over a cyclone-affected oceanic region; (2) To assess the relevance of implicit treatment of convection at two grid resolutions by analyzing the model simulated fields through a time-lagged ensemble approach.

This paper is organized into five sections. Section 1 provides details about the COSMO model with a special emphasis on the parameterization of convection adopted by the model. Section 2 describes the method, the design of sensitivity experiments in the COSMO model, and the details of the database. All the important results obtained from the present article are detailed in Sect. 3. Finally, important conclusions drawn from the present article are summarized in the last section.

\section{About the COSMO model}

The COSMO is a non-hydrostatic limited-area atmospheric prediction model that was developed at Deutscher Wetterdienst (German Weather Services) for operational NWP and various research applications on the meso- $\beta$ and meso- $\gamma$ scale [15-17]. The three dimensional non-hydrostatic governing equations of the atmosphere are solved numerically on an Arakawa C-grid [15]. The temporal integration of the governing equation is done with the Runge-Kutta scheme with a prescribed time step chosen by the user. The lowest vertical level of the model is placed at $10 \mathrm{~m}$ above the local topography and a generalized terrain following height co-ordinate system is adopted for the definition of vertical grid points above. The prognostic variables in this model include temperature, specific humidity, horizontal and vertical Cartesian wind components, pressure perturbation, cloud water content, cloud ice content, turbulent kinetic energy, specific water content of rain, snow and graupel [18]. The COSMO model includes parameterization for radiative transfer, cloud 
micro-physics, sub-grid scale turbulence, and convection. The model also includes parameterization for the ground heat and water transport and the land-atmosphere interactions. Surface-layer turbulent fluxes of momentum, heat and moisture provide a coupling between the atmospheric part of the model and the soil model. COSMO employs a stability and roughnesslength dependent formulation of surface-layer turbulent fluxes, in which an analytic procedure is applied in the flux calculation in the Prandtl layer for improved computational efficiency $[19,20]$. In the surface-layer parameterization scheme, the bulk exchange coefficients are approximated by iterative solution of analytical functions that relate these coefficients to the roughness length for momentum, heat and moisture. The magnitudes of bulk Richardson number $\left(\mathrm{Ri}_{B}\right)$ are used for the discriminating the turbulent flow from the laminar flow, and thus representing the dynamic stability of the atmosphere [21]. The formation and modification of clouds is described by a bulk micro-physics parameterization including water vapour, cloud water, and ice, rain and snow with a fully prognostic treatment of precipitation, i.e., three-dimensional transport of rain, and snow is directly calculated [22]. Condensation and evaporation are parameterized by saturation adjustment whereas depositional growth and sublimation of cloud ice are estimated using an explicit nonequilibrium growth equation. Sub-grid scale cloudiness for radiation calculations is parameterized by an empirical function depending on relative humidity, ice content, and height. Time integration in COSMO uses a second order leapfrog time-split integration approach. Different schemes of initialization are available in the COSMO model, wherein the initial and lateral boundary conditions of the atmosphere are fed to the model through a tailored sub-set of the global model's analysis and forecast fields. In the present study, we have used COSMO Version 5.05 for all simulations. This version of the model was released in April 2018. More details on the functioning of COSMO are accessible on the model's website and other published literature [13, 15-18].

\section{Methods and data}

In the present work, the initial and lateral boundary conditions of the atmosphere are extracted from the analysis and forecast fields of ICON (ICOsahedral Nonhydrostatic, a German global model) and are used for the initialization of COSMO. Further technical details on the COSMO model configuration used in the present study are described in Table 1.

\subsection{Model simulations}

The research work is focused on the performance evaluation of COSMO model for an intense rainfall episode during the passage of OCKHI-a VSCS over the central Arabian sea. The genesis of this cyclonic storm was observed over the Comorin sea in the November 2017 and afterward, the storm made north-westward progression and subsequently attained the status of a VSCS on the afternoon of 1 December 2017. The primary objective of this case study is to assess the treatment of convection in COSMO and the impact of dynamical downscaling on the precipitation fields over the central Arabian sea, which received very intense rainfall during the progression of OCKHI. Hence, a geographical region of about $1780 \mathrm{~km} \times 1780 \mathrm{~km}$ centered around the coastal Arabian sea between $66^{\circ} \mathrm{E}$ and $82^{\circ} \mathrm{E}$ longitudinal band and extending from $6^{\circ} \mathrm{N}$ to $22^{\circ} \mathrm{N}$ latitudes, is configured as the model domain. In the vertical direction, a total of 50 vertical levels are configured in COSMO with the model ceiling at an altitude corresponding to $10 \mathrm{hPa}$. The analysis fields corresponding to 00 and 12 UTC of ICON global model for a period of 3 days from 1 December 2017 to 3 December 2017 are utilized as the initial conditions for each distinct simulations, and forecast fields for $+48 \mathrm{~h}$ were generated from all individual simulations. Different meteorological fields extracted from the COSMO forecasts form the main database in this study. Different atmospheric fields of the ICON German global model are available at a horizontal grid spacing of $0.13^{\circ}$ [25-27]. Here, we have chosen the Tiedtke scheme of convection, which is a well-tested scheme and is also used as the default parameterization scheme of convection in COSMO model [28-30].

\subsection{Sensitivity experiments with NWP model}

A total of three distinct numerical sensitivity experiments are designed and carried out in the present study for addressing the impact analysis of the treatment of convection in the COSMO model. In these experiments, four distinct Analysis fields of the ICON global model corresponding to 00 and 12 UTC of 1 December, and 00 and 12 UTC of 2 December 2017, provide initial conditions to the COSMO model for simulations with a lead time of +48 $h,+36 h,+24 h$, and $+12 h$, respectively. Model simulations with different lead times are good for generation of a time-lagged ensemble. We have estimated the timelagged ensemble forecast field by taking average of different lead times for individual experiments described below. The lateral boundary conditions for all these simulations are provided by the ICON forecast fields with an interval of $3 \mathrm{~h}$. Below, we explain the details about these numerical experiments (also refer to Table 1): 

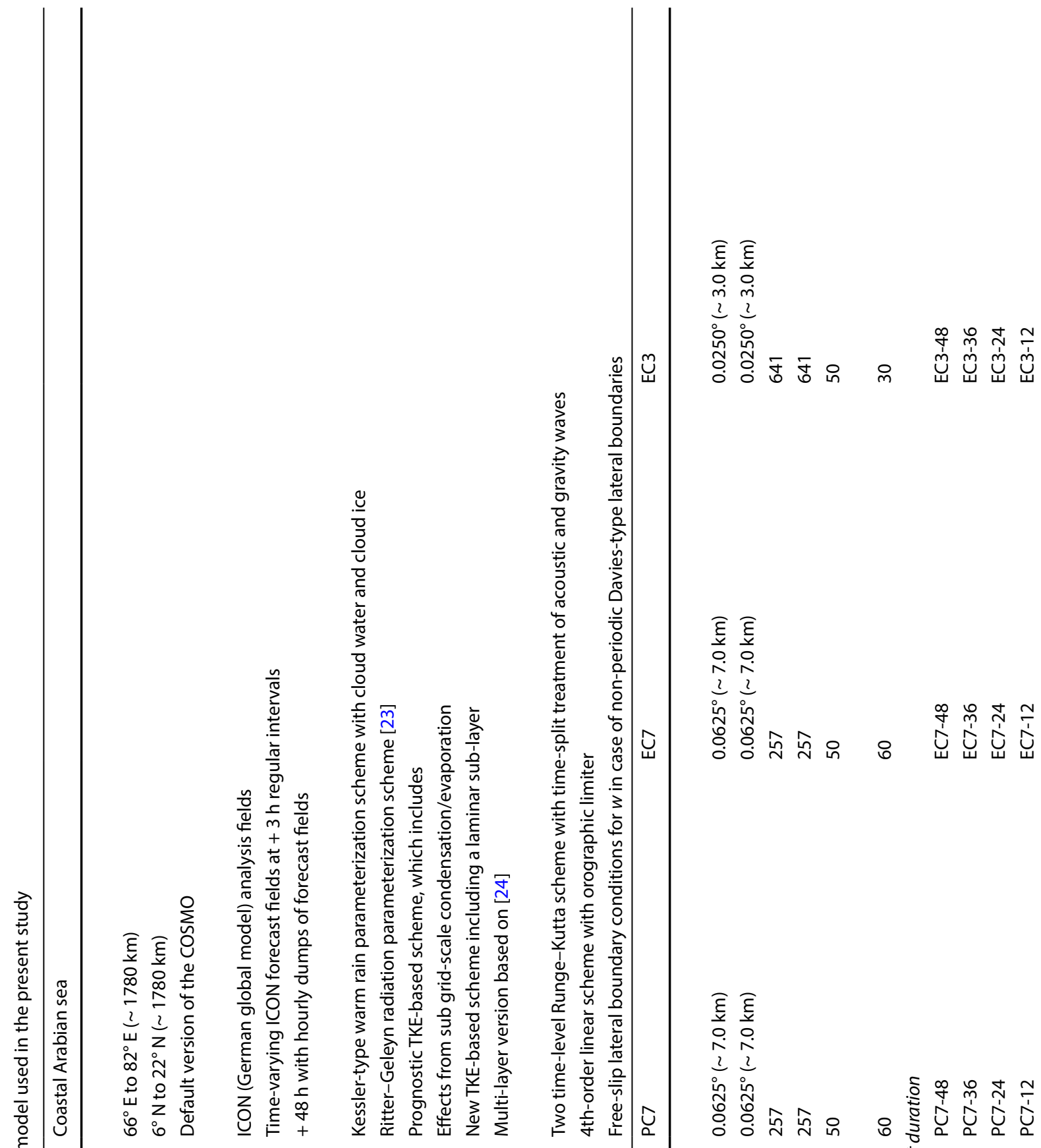

妾 $\bar{\xi}$

$\stackrel{i}{\circ} \stackrel{-1}{\circ}$

23

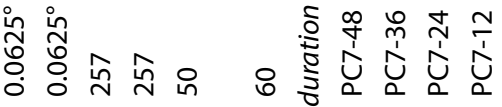

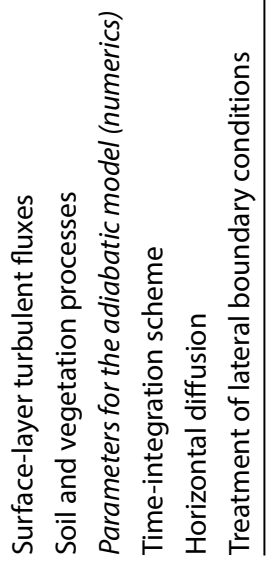
ฐิ๊

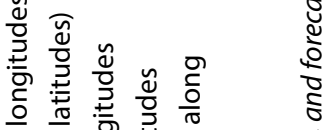

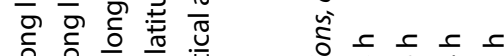

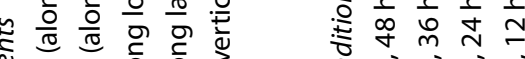

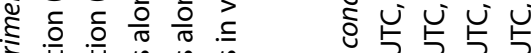
艾吉

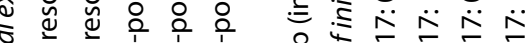

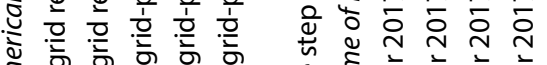

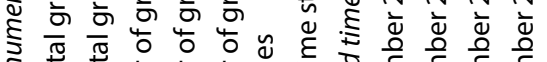

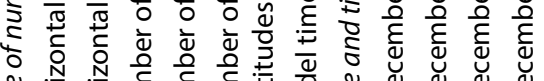

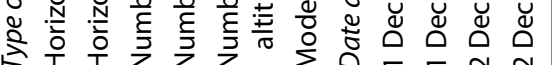


1. Parameterized convection at $\sim 7 \mathrm{~km}$ resolution $(P C 7)$ simulations

In the first set of simulations (hereafter referred to as the PC7 simulations), COSMO model is configured for a spatial grid resolution of $0.0625^{\circ}$ ( $=$ approximately $7 \mathrm{~km}$ ), and the necessary constant and varying surface/atmospheric variables are downscaled from coarse grid $\left(\sim 0.13^{\circ}\right)$ fields of ICON to a fine grid $\left(\sim 0.0625^{\circ}\right)$ of COSMO for the generation of initial and lateral boundary conditions. For PC7 simulations, convective processes are parameterized using the Tiedtke convection parameterization scheme. For capturing the severe convective episode and associated rainfall fields observed on 00 UTC of 3 December 2017, a time-lagged ensemble for four distinct simulations with different leadtimes (e.g., PC7-48 where the 48 is the leadtime in hours) are carried out.

2. Explicit treatment of convection at $\sim 7 \mathrm{~km}$ resolution (EC7) simulations

In the second set of simulations (hereafter referred to as the EC7 simulations), the grid resolution of the model is kept as same as the PC7 simulations, but the convective processes are explicitly simulated, and the provision for parameterization of convection is switched off. Similar to the previous experiment, a time-lagged ensemble forecast fields are generated with different lead times.

3. Explicit treatment of convection at $\sim 3 \mathrm{~km}$ resolution (EC3) simulations

This set of simulations (hereafter referred to as the EC3 simulations) are very similar to the EC7 simulations except for the fact that the horizontal grid resolution in this set is further reduced to $0.025^{\circ}$. In this set of simulations also, the convection parameterization scheme is switched off, and convective processes are explicitly simulated. For fine-grid spatial resolutions, it is recommended to switch off the convection parameterization scheme at horizontal grid resolutions finer than $3 \mathrm{~km}$, and the convective processes at such finer resolutions must be treated directly.

The above mentioned numerical experiments provide detailed insights on two aspects: (1) parameterized versus explicit convection; and (2) assessment of model resolution for convective-permitting model simulations through a time-lagged ensemble of forecast fields with different leadtimes.

\subsection{Observations}

For the validation of model-simulated forecast fields, we have made use of two standard global reanalysis fields, namely-ERA5 (European Centre for Medium Range
Weather Forecasts Reanalysis) and National Center for Atmospheric Research (NCEP) Global Data Analysis System (GDAS) FNL (Final) 0.25 Degree Global Tropospheric Analyses and Forecast Grids (hereafter referred to as the FNL reanalysis). Both these reanalysis fields are widely used and accepted for the validation of regional NWP model simulations [31, 32]. In the present study, we have examined the basic meteorological parameters such as sea level pressure, surface winds, air temperature, and accumulated rainfall from the reanalysis data for the validation of COSMO model simulations.

In addition to these reanalysis fields, we have also made use of satellite-based precipitation measurements obtained from the Integrated Multi-satellitE Retrievals for GPM (IMERG) for the validation of accumulated rainfall from different configurations of the COSMO $[33,34]$. Here, we have used IMERG Level-3 data for the validation of $24 \mathrm{~h}$ accumulated rainfall measurements. In addition to the above-mentioned fields, we have also made use of the best track data from the India Meteorological Department (IMD, http://www.imd.gov.in) on the time progression of OCKHI including the exact location of the eye of the storm. Maximum sustained surface winds and the estimated central pressure of the cyclonic core data are also taken from the IMD report.

\section{Results and discussion}

\subsection{Intense convective precipitation episode over the coastal Arabian sea}

OCKHI was one of the rarest cyclonic storms with its total life span of $162 \mathrm{~h}$ during which it traveled a distance of $2538 \mathrm{~km}$ over the Arabian sea [13, 14]. Historically speaking, none of the Depressions or Cyclonic Storms formed in the month of December over the Comorin Sea ever became a VSCS in the last 100 years. OCKHI attained the status of a Cyclonic Storm from the stage of a Depression within $6 \mathrm{~h}$. Its rapid intensification was extremely unusual compared to normal storms. After attaining the status of VSCS, a broad region of the central Arabian sea received intense rainfall from 1 December 2017 to 5 December 2017. Due to its long life span and associated intense rainfall over the central Arabian sea, this cyclonic event becomes an ideal case for investigation on the treatment of convection in COSMO model. We have chosen a geographical area over the Arabian sea as the model domain centered over the region covering the convective events from 2 December to 3 December 2017 (see Fig. 1). Spatial fields of $24 \mathrm{~h}$ accumulated rainfall for 00 UTC of 3 December 2017 obtained from PC7 simulations are shown in background in Fig. 1 for a quick assessment 


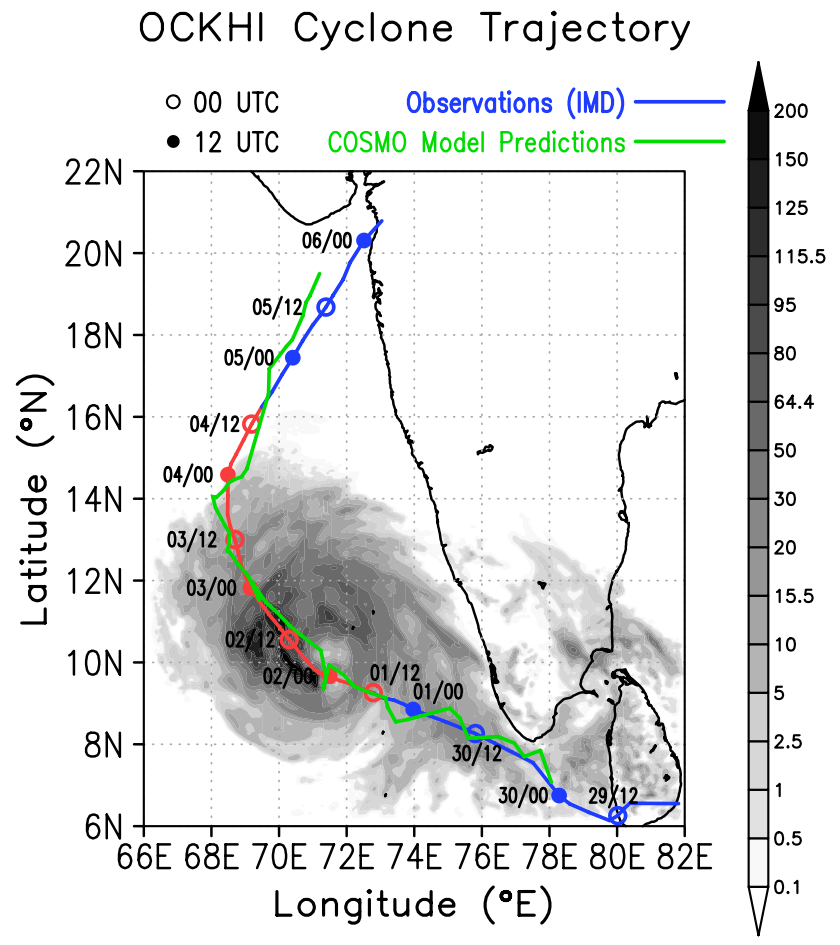

Fig. 1 Geographical domain of the COSMO model. The background colour map shows $24 \mathrm{~h}$ accumulated precipitation $(\mathrm{mm})$ on 00 UTC of 3 December 2017. The trajectory of OCKHI cyclonic storm from its formation as a depression on 29 November 2017 to its landfall and dissipation on 6 December 2017 is also overlaid on the plot. The trajectory along which the storm was categorized as a VSCS, is marked in red colour. Predicted trajectory of the storm through PC7 configuration of COSMO is marked in green colour

of the convective episode. The progression of OCKHI cyclonic storm from its formation as a depression on the early morning of 29 November 2017 to its final landfall and dissipation on 6 December 2017 are also marked along the trajectory. After its genesis, the storm gained intensity and moved north to north-westward and finally became a VSCS on the afternoon of 1 December 2017. During its passage over the coastal Arabian sea from 29 November 2017 to 3 December 2017, the storm moved north-westward, yielding in heavy $(64.5-115.5 \mathrm{~mm})$ to very heavy (> 115.5 $\mathrm{mm}$ ) precipitation over the central Arabian sea. Top row of Fig. 2 depicts $+24 \mathrm{~h}$ forecasted accumulated rainfall over the model domain for 00 UTC of 3 December 2017 as seen in (a) satellite-based GPM IMERG observation, (b) ERA5 reanalysis field and (c) FNL reanalysis field. We also show the concurrent $+48 \mathrm{~h}$ and $+24 \mathrm{~h}$ advanced COSMO forecasts in the bottom row of Fig. 2d, e, respectively. The track of $\mathrm{OCKHI}$ is also overlaid on the spatial maps of $24 \mathrm{~h}$ accumulated rainfall in Fig. 2. The OCKHI storm remained as a VSCS during this episode and made a north-westward movement of about $350 \mathrm{~km}$ within $24 \mathrm{~h}$. Satellite-based IMERG observation of precipitation, as well as the model-based
ERA5 and FNL reanalysis field also indicated heavy to very heavy rainfall over the central Arabian sea along the observed track of OCKHI storm (top row of Fig. 2). It may also be noted that COSMO model simulations with a lead time of $+24 \mathrm{~h}$ as well as $+48 \mathrm{~h}$ shown in the bottom rows of Fig. 2 also indicated wide-spread heavy rainfall. Based on the intensity of convection, and category of OCKHI on these days, we have confirmed the severe convective precipitation episode from 00 UTC of 2 December 2017 to 00 UTC of 3 December 2017 over the Lakshadweep islands and the central Arabian sea as the primary case for investigation of the treatment of convection in COSMO model based on different initial conditions.

\subsection{Simulation of sea level pressure and wind fields}

Based on the IMD bulletin number 30 (BOB 07/2017), the OCKHI cyclonic storm was very active on 00 UTC of 3 December 2017, and its category was retained as a VSCS. On this day, there was a noticeable pressure drop of more than $15 \mathrm{hPa}$ around the center of the storm, and the maximum sustained surface winds were reported to be as high as 86 knots. Figure 3 compares the spatial maps of sea level pressure and $10 \mathrm{~m}$ horizontal wind fields simulated by COSMO, with the global datasets. The top row depicts the spatial maps of sea level pressure and wind fields inferred from the global models whereas the bottom row shows the time-lagged ensemble mean of COSMO model predictions with lead times of 48-, 36-, 24-h and 12-h.

Spatial maps of sea level pressure inferred from the ERA5 and FNL reanalysis as well as the ICON analysis clearly showed the presence of a prominent low-pressure region with a pressure drop of more than $15 \mathrm{hPa}$ over the central Arabian sea. The location of the low-pressure region simulated by three global models were lying within a range of about $50 \mathrm{~km}$ from the actual location reported by the IMD. In the case of the ICON analysis field, the deviation between the inferred and observed eye of the cyclone was $41.7 \mathrm{~km}$. All three configurations of COSMO model simulations could clearly capture the presence of an intense lowpressure system, indicating the potential of the COSMO model in early prediction of the storm and its intensity. Interestingly, COSMO model simulations with three distinct configurations do not show any large or significant differences among themselves in terms of the intensity and location of the low-pressure region. This indicates that simulation of large-scale feature is more important in such cases rather than representation of fine-scale features.

The top row of Fig. 3 represents three truths about the prevailing meteorological conditions through global models, which showed identical large-scale features, but differed from each other in terms of the magnitudes of the storm. ERA5, FNL and ICON global models clearly indicated 

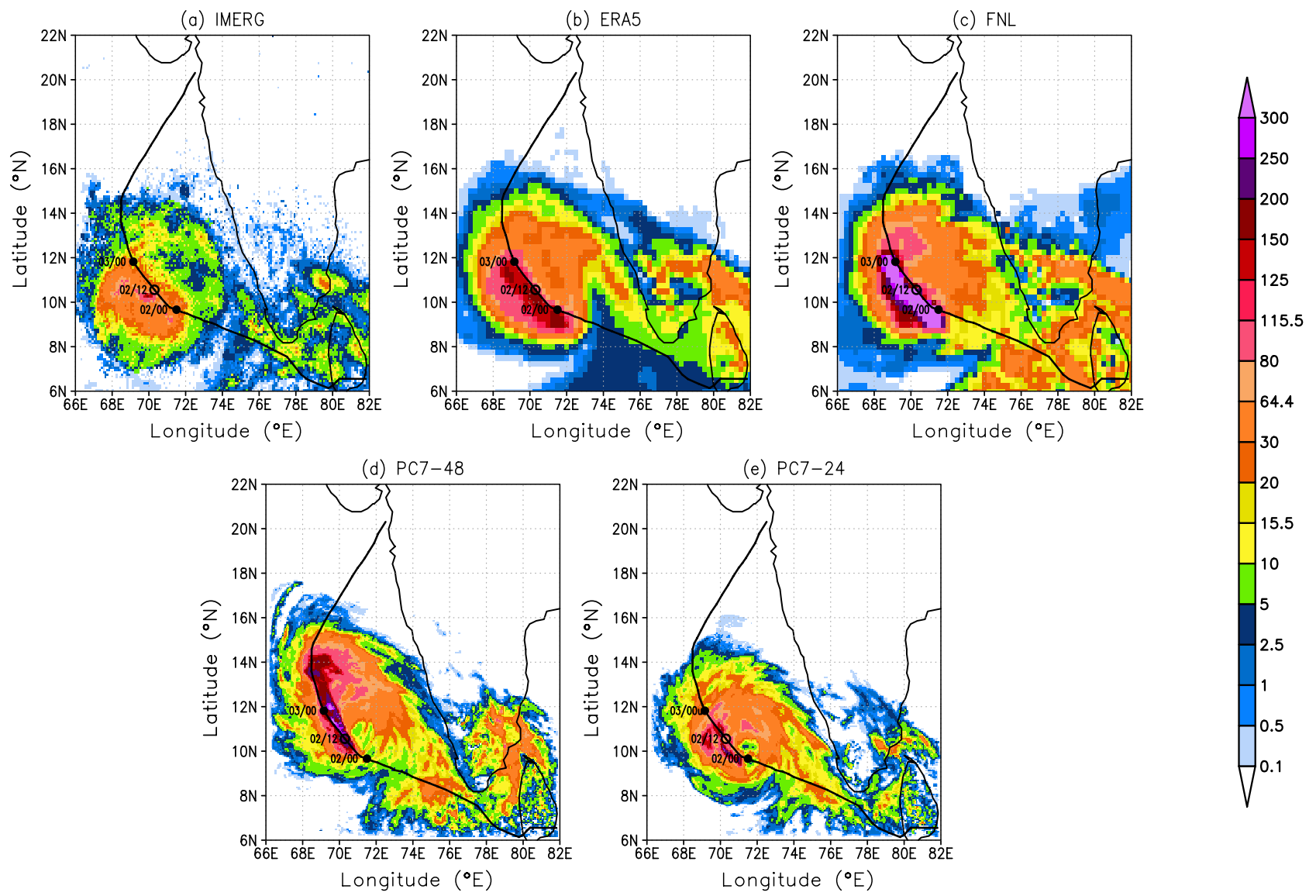

accumulated rainfall for the same period as shown in the top row by COSMO model with PC7 configuration with a lead time of +48 and $+24 \mathrm{~h}$ based on the initial conditions of 00 UTC of 1 December 2017 and 2 December 2017, respectively ated with the passage of $\mathrm{OCKHI} ; \mathbf{b}, \mathbf{c}$ concurrent precipitation maps from the ERA5 and FNL reanalysis; d, e advanced prediction of $24 \mathrm{~h}$

the presence of a low-pressure system, but the magnitude of associated wind speeds ranged from 32 to 80 knots. In contrast to this, the differences in the magnitudes of the storm simulated by three distinct configurations of COSMO were very minimal, as against large differences between the global datasets. The wind fields inferred from the ICON analysis (Fig. 3c) show a well-established counter-clockwise cyclonic circulation with the magnitudes of maximum sustained winds ranging between 34 to 40 knots only, whereas it ranged between 40 and 64 knots in the case of COSMO model simulations.

With a view to quantifying the impact of dynamical downscaling of the COSMO model from ICON fields, we show time-series plot of the estimated central pressure of the cyclonic storm and maximum sustained surface winds (Wind Speed $_{\text {maximum }}$ ) in Fig. 4. As OCKHI attained the status of VSCS on 12 UTC of 1 December, the central pressure over the eye of the cyclonic storm further dipped from 986 to $976 \mathrm{hPa}$ on 6 UTC of 2 December 2017. In the case of ICON forecasted fields, the simulated core pressure was in the range of 989-991 $\mathrm{hPa}$. However, the regional NWP model COSMO with three configurations yields core pressure to a minimum of about $984 \mathrm{hPa}$, which is substantially better than the ICON fields. Nonetheless, it has to be noted that the estimated core pressure from COSMO was still higher than the actual observed central pressure. Figure $4 \mathrm{~b}$ shows the maximum sustained surface winds from the ICON and COSMO fields, together with the concurrent IMD observations. In the case of COSMO and ICON models, Wind Speed maximum $_{\text {is taken as the peak wind speed }}$ within an interval of $1 \mathrm{~h}$. Traditionally, IMD uses the highest 3 min surface wind occurring within the circulation of the system. An inter-relationship between the central pressure deficit and the peak surface wind speed during the tropical cyclones, is a long-standing topic of investigation which is approximated empirically but lacks physical understanding $[35,36]$. Here, we observe that the magnitudes of maximum sustained winds simulated by ICON 

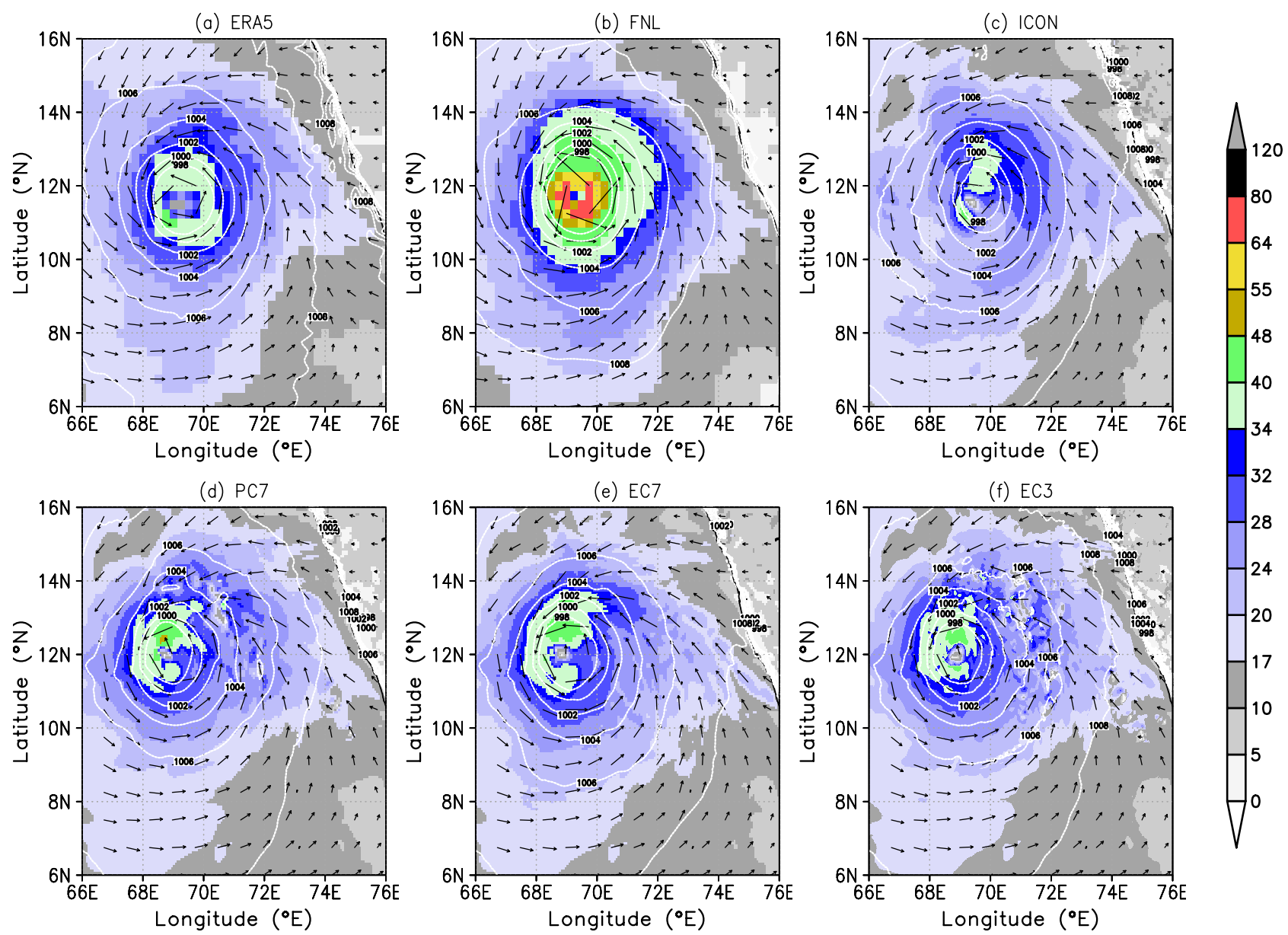

Fig. 3 Sea level pressure (in $\mathrm{hPa}$ ) and maximum sustained surface wind speed (in m/s) corresponding to 00 UTC of 3 December 2017 in a ERA5 reanalysis, b FNL reanalysis; and c ICON analysis fields.

were relatively lower than the concurrent values obtained from three distinct configurations of COSMO. These differences can be attributed to the wind-pressure relationship, as the magnitudes of estimated central pressure in ICON simulations were higher than that of the COSMO. During the first $24 \mathrm{~h}$ of simulations, $7-\mathrm{km}$ resolution of the COSMO model configuration with the parametrized and the explicit treatment of convection yield almost similar magnitudes of Wind Speed maximum, $_{\text {, wheas the }}$ 3-km configuration allows the system to become more intense. Even though the observed wind speeds were not so intense as that seen in the EC3 configuration, it is an interesting observation to note that the finer resolution allows the tropical storm to become more intense, which is likely to be a systematic impact of the finer resolution. A comprehensive examination of the sea level pressure and winds clearly indicates the intensity of OCKHI was underestimated by the ICON model, which is improved in the dynamically downscaled COSMO model simulations. d-f a time-lagged ensemble mean forecast of different lead times obtained from COSMO for PC7, EC7 and EC3 simulations

\subsection{Simulation of precipitation fields for 00 UTC of 3 December 2017}

Traditionally, the rain guages are considered as the most accurate way of measuring the rainfall, but logically it is not possible to have a network of raingauges over oceanic regions, therefore the satellite instruments provide a good alternative for the estimation of reality through remote sensing techniques. Figure 5 depicts $24 \mathrm{~h}$ accumulated rainfall between 00 UTC of 2 December to 00 UTC of 3 December 2017 from satellite-based IMERG data, ERA5 reanalysis and $\mathrm{FNL}$ analysis data, together with the concurrent predictions of COSMO through PC7, EC7 and EC3 configurations. The top row of Fig. 5 depicts three different types of rainfall estimations. The IMERG fields are satellite derived rainfall, while the ERA5 and FNL provide the estimation of rainfall through two distinct global models. Even though the IMERG data provides a reliable estimation of the rainfall, it can only be treated as a satellite estimation 

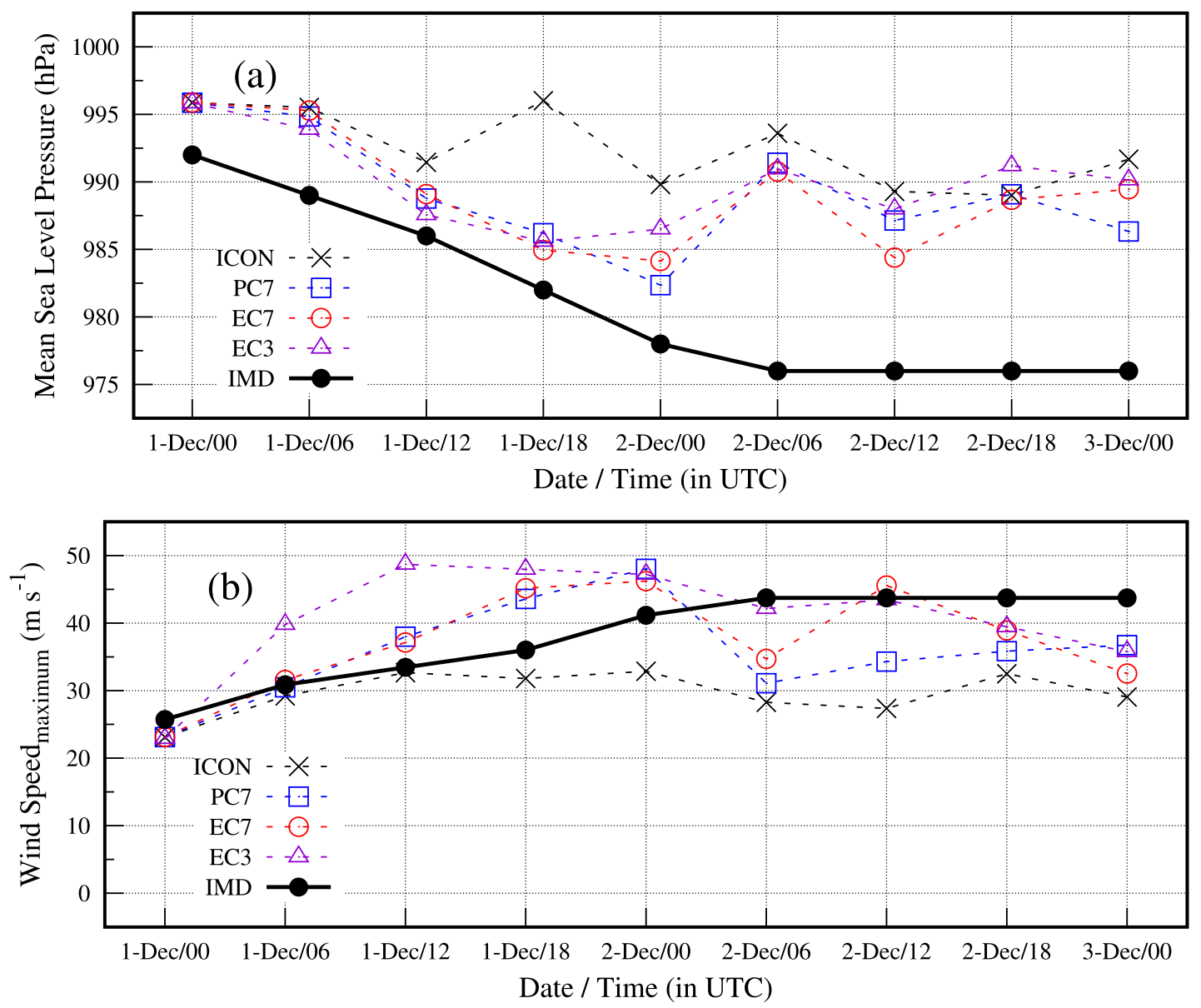

Fig. 4 a Time-series plot of minimum central pressure (in hPa) observed over the core of cyclonic storm through ICON fields and COSMO simulations, together with the estimated central pressure by IMD. b Same as $\mathbf{a}$, but for the maximum sustained surface winds (in $\mathrm{m} / \mathrm{s}$ )

of the reality, whereas the ERA5 and FNL derived rainfall are two other alternative ways of estimating the reality. $A$ comparison of the rainfall estimated through differnt configurations of the COSMO model with satellite and global model data would provide us deep insights on the probable uncertainties in the estimation of rainfall during such a severe weather event. Broadly speaking, the rainfall estimated by IMERG and two global models showed a similar pattern of the accumulated rainfall, but the magnitudes were not similar.

The COSMO model simulations with PC7, EC7 and EC3 configurations indicating $24 \mathrm{~h}$ accumulated rainfall with a lead time of $+24 \mathrm{~h}$ are shown in the second row of Fig. 5. The parameterized convective simulation PC724 yield fairly widespread rainfall over the central Arabian sea similar to that seen in the IMERG data. The EC7 and EC3 configurations of the COSMO allowed us to switch off the convection parameterization scheme, resulting in 24 $h$ accumulated precipitation maps shown in the second row of Fig. 5. Both these configurations result in a lack of rainfall for a broader region of the model domain. In general, the area with heavy precipitation is confined to a very small region across the track of OCKHI in EC7 and EC3 simulations. One of the important conclusions from this comparison is that the difference between in the estimated rainfall between EC7 and EC3 is much smaller than the difference between EC7 and PC7. This indicates that the impact of representation of convection appears to be more important than the spatial resolution of the model.

The rainfall maps obtained from IMERG observations and COSMO model simulations are categorized into standard classes of accumulated rainfall and are shown in Fig. 6. Based on the rainfall category map corresponding to IMERG observations (Fig. 6a), it can be noticed that about $52 \%$ of the grid points are rain-free. Among the grid points with rain, very light to moderate rain grid points were spread almost in a uniform fashion, while there were only a very few grid points (less than $3 \%$ ) amounting to relatively high to very high rain category. In the case of PC7 simulations (Fig. 6b), the proportion of rain-free grid points was 

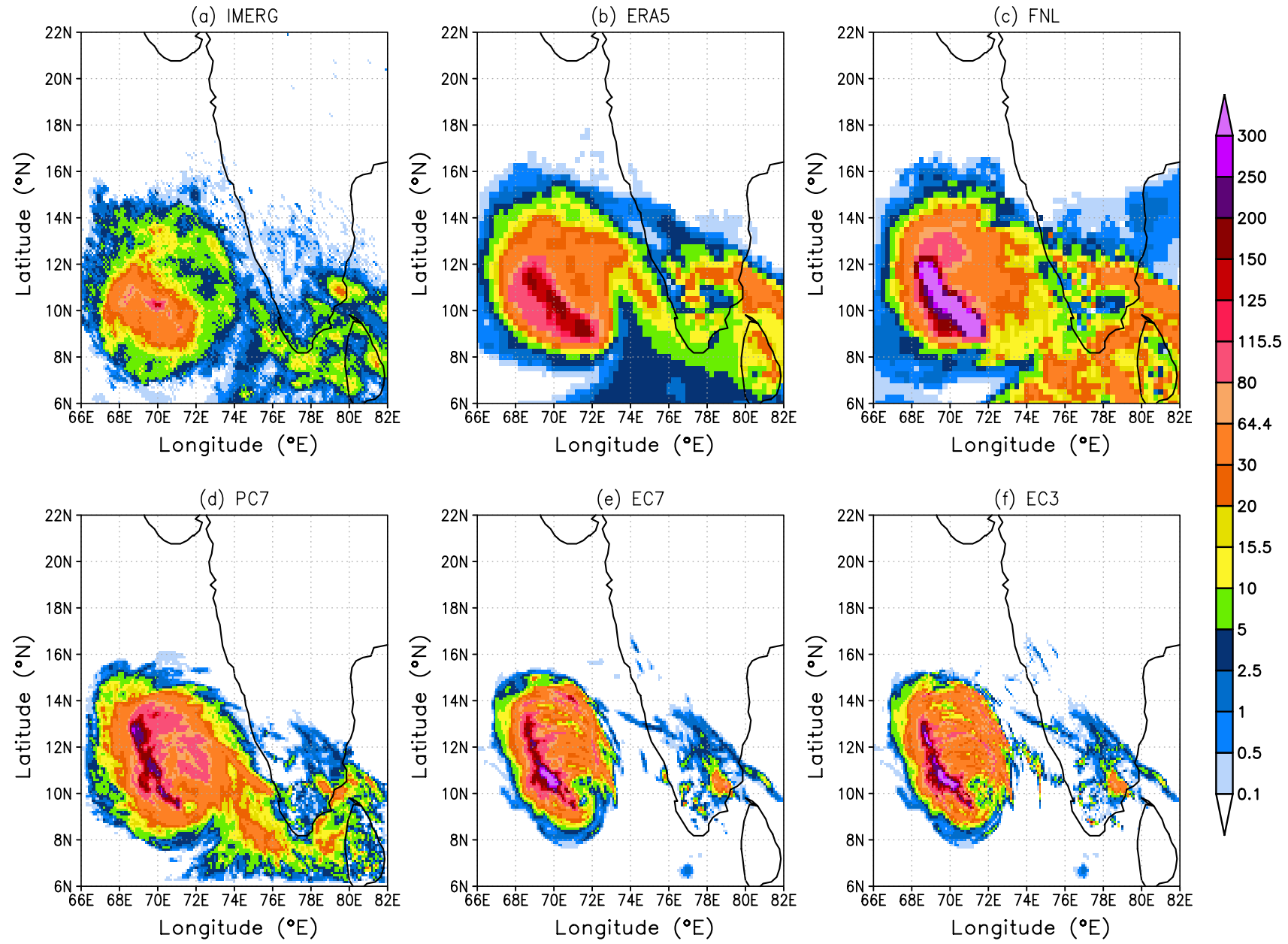

Fig. $524 \mathrm{~h}$ accumulated rainfall (in mm), from 00 UTC of 2 December 2017 to 00 UTC of 3 December 2017 extracted from a satellitebased IMERG data, b ERA5 reanalysis, c FNL reanalysis; bottom row:

about $60 \%$, larger than the IMERG observations. Share of very light rain to moderate rain in this simulation was more or less uniform and was comparable to the IMERG observations. However, the percentage of grid points amounting to relatively high to extremely high rain class was higher than the IMERG observations. COSMO model simulations with an explicit treatment of convection (i.e., EC7 and EC3) (Fig. 6c, d) yielded a larger proportion of rain-free grid points as against the simulations with implicit treatment of convection. Both the EC7 and EC3 simulations resulted in extremely heavy rainfall ( $>244.5 \mathrm{~mm}$ ) for a few grid points, whereas the IMERG observations did not show any grid point with such a large value of precipitation.

In one of the regime-dependent evaluation studies of the accumulated precipitation in COSMO, Akkermans et al. [28] have evaluated two variants of the COSMO: a fine-resolution version ( $2.8 \mathrm{~km}, \mathrm{COSMO}-\mathrm{DE})$ and a coarseresolution version ( $7 \mathrm{~km}$, COSMO-EU) for the German d-f concurrent $+24 \mathrm{~h}$ predictions based on PC7, EC7 and EC3 simulations, respectively

region. They observed a strong over-estimation of the precipitation fields by COSMO-EU, whereas a positive bias was identified on top of topographical features such as the mountains and hill ridges. One of the plausible causes for differences in the convection parameterization scheme was discussed as the graupel scheme in COSMO$\mathrm{DE}$, which might lead to over-estimation of the precipitation subject to the formation of quick precipitation in the form of graupel [28]. In this context, our investigation yields reduced precipitation over the coastal Arabian sea when the convective processes are dealt explicitly and the parameterization scheme for moist convection is switched off. Champion and Hodges [37] have investigated some of the important problems associated with dynamical downscaling of the Met Office Unified Model by looking at the optimum configuration for obtaining the distribution and intensity of a precipitation field to match observations. Their study has shown that realistic precipitation 

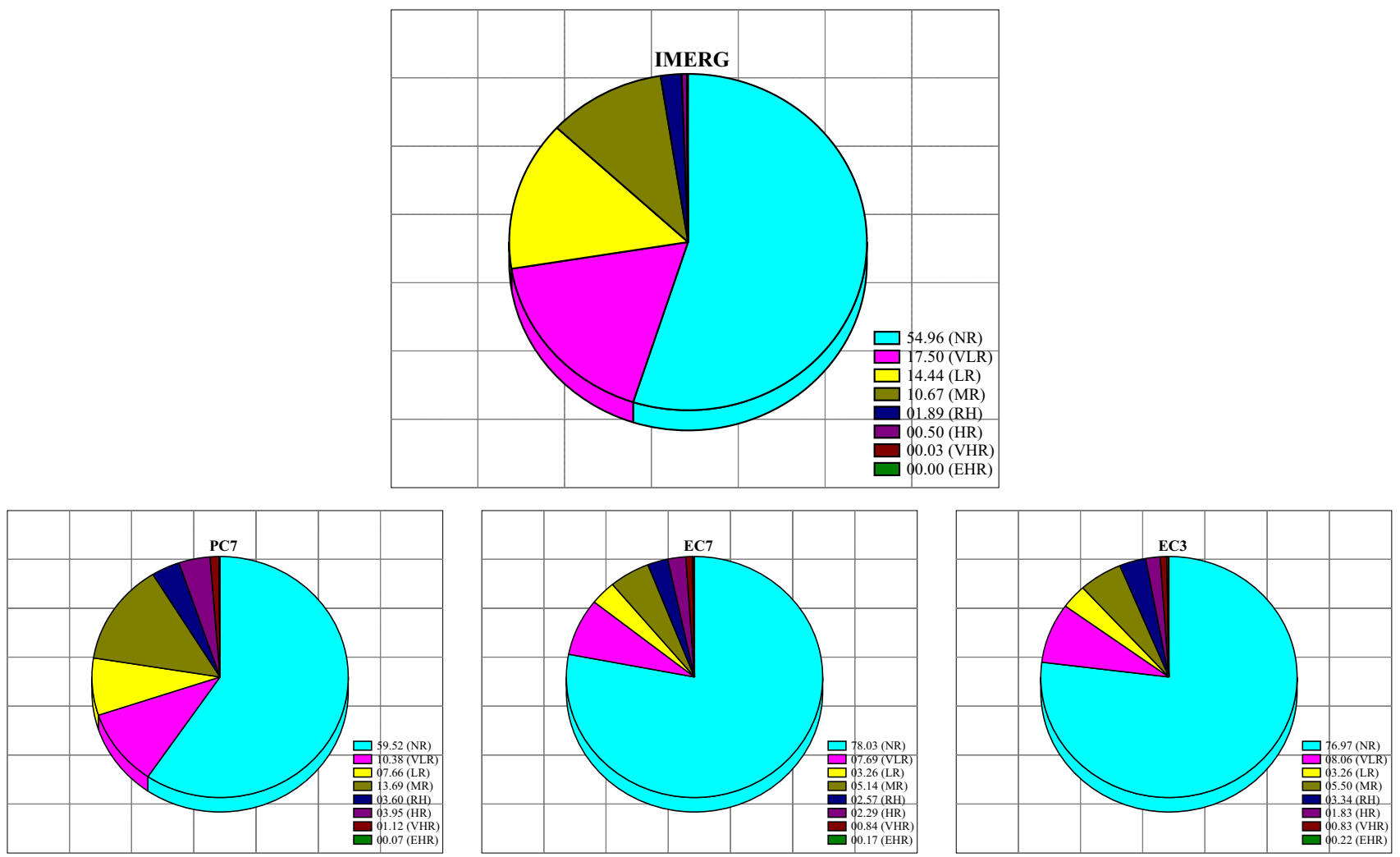

Fig. 6 Pie-chart of standard rain classification for the study domain as observed in IMERG and three different configurations of COSMO (i.e., PC7, EC7 and EC3). Rain categories are classified as: no rain (NR, $0 \mathrm{~mm}$ ); very light rain (VLR, 0.1-2.4 $\mathrm{mm})$; light rain ( $L R, 2.5-7.5 \mathrm{~mm})$;

intensities can be obtained using a high-resolution Limited area model-driven from a coarse resolution global model.

\subsection{Track error analysis for PC7, EC7 and EC3 simulations}

In this section, we present the track error analysis for three different configurations of COSMO as a function of lead time taken by the model for prediction of the location of the cyclonic storm. Subrahamanyam et al. [14] have shown a mean deviation of $74 \mathrm{~km}$ between the observed and predicted eye of the cyclone for a lead time of $+24 \mathrm{~h}$ from the genesis of OCKHI to its final dissipation stage. For a detailed assessment of the impact of dynamical downscaling and explicit treatment of convection in the COSMO model, we evaluate the predicted and observed eye of the cyclone on 00 UTC of 3 December 2017 for PC7, EC7 and EC3 configurations with different lead times. As per the IMD reports, the eye of the cyclone was located at $11.82^{\circ} \mathrm{N}, 69.15^{\circ} \mathrm{E}$ on 00 UTC of 3 December 2017. Predicted location of the eye of the cyclonic storm for different initial conditions corresponding to +48 to $+12 \mathrm{~h}$ lead time for PC7, EC7, moderate rain ( $M R, 7.6-35.5 \mathrm{~mm})$; relatively heavy $(\mathrm{RH}, 35.6-64.4$ $\mathrm{mm})$; heavy rain (HR, 64.5-124.4 $\mathrm{mm}$ ); very heavy rain (VHR, 124.5$244.4 \mathrm{~mm}$ ); extremely heavy rain (EHR, $>244.5 \mathrm{~mm}$ )

and EC3 simulations are tabulated in Table 2. The estimated deviation between the predicted and observed eye of the cyclone is also shown as a function of lead time in the Table. Deviations in the track error for $+12 \mathrm{~h}$ is partially attributed to the spin-up of COSMO and initial/lateral boundary conditions provided to the model. Even though the prediction of low-pressure regime associated with the eye of the cyclone is not directly related with the treatment of moist convection, we notice a small improvement in the time-lagged EC7 and EC3 runs, as against the $P C 7$ runs. Further, the track difference between all three configurations of COSMO are relatively small.

Based on the overall assessment of the COSMO model for implicit and explicit treatment of convection with regard to the track error as well as the magnitudes of estimated rainfall three different experiments, it can be concluded that the impact of explicit representation of convection is more important than the grid resolution of the model, as the results obtained for EC7 and EC3 configurations yielded similar pattern of rainfall as well as the track of the storm. 
Table 2 Differences (in $\mathrm{km}$ ) between the observed and concurrent simulated coordinates of the eye of the cyclone by PC7, EC7 and EC3 configurations of COSMO

\begin{tabular}{|c|c|c|c|c|c|c|c|c|c|}
\hline \multirow[t]{3}{*}{ Lead time } & \multicolumn{9}{|c|}{ Predicted location of the eye of the Ockhi cyclone by COSMO } \\
\hline & \multicolumn{3}{|l|}{ PC7 } & \multicolumn{3}{|l|}{ EC7 } & \multicolumn{3}{|l|}{ EC3 } \\
\hline & Latitude $\left({ }^{\circ} \mathrm{N}\right)$ & $\begin{array}{l}\text { Longitude } \\
\left({ }^{\circ} \mathrm{E}\right)\end{array}$ & $\begin{array}{l}\text { Deviation } \\
(\mathrm{km})\end{array}$ & $\begin{array}{l}\text { Latitude } \\
\left({ }^{\circ} \mathrm{N}\right)\end{array}$ & $\begin{array}{l}\text { Longitude } \\
\left({ }^{\circ} \mathrm{E}\right)\end{array}$ & $\begin{array}{l}\text { Deviation } \\
(\mathrm{km})\end{array}$ & $\begin{array}{l}\text { Latitude } \\
\left({ }^{\circ} \mathrm{N}\right)\end{array}$ & $\begin{array}{l}\text { Longitude } \\
\left({ }^{\circ} \mathrm{E}\right)\end{array}$ & $\begin{array}{l}\text { Deviation } \\
(\mathrm{km})\end{array}$ \\
\hline $\begin{array}{l}48 \mathrm{~h} \text { Fore- } \\
\text { cast }\end{array}$ & 13.500 & 68.375 & 204.92 & 13.375 & 68.437 & 189.47 & 13.500 & 68.500 & 184.230 \\
\hline $\begin{array}{l}36 \mathrm{~h} \text { Fore- } \\
\text { cast }\end{array}$ & 13.437 & 68.500 & 193.252 & 13.437 & 68.562 & 190.880 & 13.400 & 68.600 & 185.606 \\
\hline $\begin{array}{l}24 \mathrm{~h} \text { Fore- } \\
\text { cast }\end{array}$ & 12.562 & 68.937 & 85.759 & 12.437 & 69.062 & 69.340 & 12.375 & 69.050 & 62.683 \\
\hline $\begin{array}{l}12 \mathrm{~h} \text { Fore- } \\
\text { cast }\end{array}$ & 12.000 & 68.875 & 36.009 & 12.000 & 68.687 & 54.173 & 11.925 & 68.775 & 42.457 \\
\hline $\begin{array}{l}\text { Time-lagged } \\
\text { ensemble }\end{array}$ & 12.874 & 68.672 & 128.000 & 12.795 & 68.687 & 119.000 & 12.800 & 68.731 & 118.000 \\
\hline
\end{tabular}

IMD had reported the eye of the cyclone at $11.82^{\circ} \mathrm{N}, 69.15^{\circ} \mathrm{E}$ for 00 UTC of 3 December 2017

\section{Conclusion}

In this research work, we assess the value of implicit and explicit treatment of convection in a regional NWP model COSMO during the passage of a VSCS over the coastal Arabian sea. We have also attempted to investigate the role of initial conditions with different lead times in the prediction of severe weather alerts by preparation of a time-lagged ensemble forecast field, which helped us to determine the performance of COSMO model with three distinct configurations. Presently, there is no acceptable clarity about the spatial grid resolution of an atmospheric model at which the convective processes can be directly resolved. There is a good consensus that the use of high horizontal resolution improves weather and climate simulations in many ways, and tropical cyclones can be better resolved with finer grid spacing. In the present case, explicit treatment of convection in the COSMO model led to improved prediction of the cyclonic event in terms of sea level pressure, maximum sustained surface wind speeds and the accumulated rainfall, but reduction of the spatial grid resolution from 7 to $3 \mathrm{~km}$ did not show appreciable differences in the forecast fields. A fine representation of orographic information leads to improved precipitation patterns over the land regions, but the present study conducted over the oceanic region yields no significant improvements in the forecast fields with fine grid resolution.

In NWP models, dynamical downscaling is considered as a useful approach to capture and assess the potential impact of these severe weather events. Hence, it is important to understand under what conditions the dynamical downscaling is really capable of improving the model's credibility or can reproduce weather extremes in an efficient manner compared to the coarse grid model. While choosing a regional NWP model at a very fine resolution, the modeler also needs to strike a good balance between the implicit and explicit treatment of convection. In this context, the present article provides a valuable impact analysis of the implicit and explicit treatment of convection in COSMO at higher resolution. Based on a comprehensive examination of different spatial maps of meteorological parameters simulated through the implicit and explicit treatment of convection at a resolution of $7 \mathrm{~km}$, the current study recommends switching off the convection parameterization scheme for improved predictability of severe weather events such as tropical cyclones.

Acknowledgements The COSMO model is developed by the German Weather Service and is available to the users' community for scientific and research purposes after attaining a scientific license. Model details can be accessed through its website (http://www. cosmo-model.org/). Space Physics Laboratory (SPL) has a scientific license for utilization of the COSMO model in research mode, and the authors are thankful to the Deutscher Wetterdienst (DWD, German Weather Service) for providing the initial and lateral boundary conditions from the ICON global model for this study. We express our sincere gratitude to Drs. Ulrich Schattler, Detlev Majewski and their colleagues from Deutscher Wetterdienst, Germany for their continuous support in smooth operations of COSMO at SPL. The ERA5 reanalysis data fields used in this article are part of ECMWF's Meteorological Archive and Retrieval System (MARS), which is accessible to registered users in the ECMWF Member States and the Cooperating States from the ECMWF Data Server at http://data.ecmwf.int/data. The FNL reanalysis data for this study are from NCEP FNL Operational Model Global Tropospheric Analyses of the Research Data Archive (RDA) which is maintained by the Computational and Information Systems Laboratory (CISL) at the National Centers for Environmental Prediction/National Weather Service/NOAA/U.S. The original data are available from the RDA (https://doi.org/10.5065/D6M04 3C6). The satellite-based GPM IMERG data is accessed through Goddard Earth Sciences Data and Information Services Center. Authors duly acknowledge the above centers for making the reanalysis fields and precipitation data available in the public domain through their 
services. One of the authors Roshny is thankful to the Indian Space Research Organisation for her Ph.D. research fellowship. We would also like to thank the anonymous reviewers for their valuable suggestions and comments which helped us to improve the quality of this research paper.

\section{Compliance with ethical standards}

Conflict of interest The authors declare that they have no conflict of interest.

\section{References}

1. Yu X, Lee TY (2010) Role of convective parameterization in simulations of a convection band at grey-zone resolutions. Tellus $A$ Dyn Meteorol Oceanogr 62(5):617-632. https://doi.org/10.111 1/j.1600-0870.2010.00470.x

2. Jeworrek J, West G, Stull R (2019) Evaluation of cumulus and microphysics parameterizations in WRF across the convective gray zone. Weather Forecast 34(4):1097-1115. https://doi. org/10.1175/WAF-D-18-0178.1

3. Bryan GH, Wyngaard JC, Fritsch JM (2003) Resolution requirements for the simulation of deep moist convection. Mon Weather Rev 131(10):2394-2416

4. Field PR, Brozkova R, Chen M, Dudhia J, Lac C, Hara T, Honnert R, Olson J, Siebesma P, de Roode S, Tomassini L, Hill A, McTaggart-Cowan R (2017) Exploring the convective grey zone with regional simulations of a cold air outbreak. Q J R Meteorol Soc 143(707):2537-2555. https://doi.org/10.1002/qj.3105

5. Lim YK, Schubert SD, Reale O, Lee MI, Molod AM, Suarez MJ (2015) Sensitivity of tropical cyclones to parameterized convection in the NASA GEOS-5 model. J Clim 28(2):551-573. https:// doi.org/10.1175/JCLI-D-14-00104.1

6. Yu X, Lee T (2011) Role of convective parameterization in simulations of heavy precipitation systems at grey-zone resolutions-case studies. Asia Pac J Atmos Sci 47:99-112. https:// doi.org/10.1007/s13143-011-0001-3

7. Vasconi M, Montani A, Paccagnella T (2018) Sensitivity of forecast skill to the parameterisation of moist convection in a limited-area ensemble forecast system. Nonlinear Process Geophys Discussions 2018:1-14. https://doi.org/10.5194/npg-2018-21

8. Smith RK (2000) The role of cumulus convection in hurricanes and its representation in Hurricane models. Rev Geophys 38(4):465-489. https://doi.org/10.1029/1999RG000080

9. Stensrud DJ (2007) Parameterization schemes: keys to understanding numerical weather prediction models. Cambridge University Press, Cambridge

10. Clark P, Roberts N, Lean H, Ballardb SP, Charlton-Perezb C (2016) Review convection-permitting models: a step-change in rainfall forecasting. Meteorol Appl 23:165-181. https://doi.org/10.1002/ met.1538

11. Fosser G, Khodayar S, Berg P (2015) Benefit of convection permitting climate model simulations in the representation of convective precipitation. Clim Dyn 44(1):45-60. https://doi. org/10.1007/s00382-014-2242-1

12. Yoo J, Galewsky J, Camargo SJ, Korty R, Zamora R (2016) Dynamical downscaling of tropical cyclones from CCSM4 simulations of the last glacial maximum. J Adv Model Earth Syst 8:1229-1247. https://doi.org/10.1002/2016MS000685

13. Roshny S, Bala Subrahamanyam D, Anurose TJ, Ramachandran $R$ (2018) Impact analysis of dynamical downscaling on the treatment of convection in a regional NWP model-COSMO: a case study during the passage of a very severe cyclonic storm
OCKHI. Nat Hazards Earth Syst Sci Discus 2018:1-26. https://doi. org/10.5194/nhess-2018-288

14. Subrahamanyam DB, Ramachandran R, Nalini K, Paul FP, Roshny $S$ (2019) Performance evaluation of COSMO numerical weather prediction model in prediction of OCKHI-one of the rarest very severe cyclonic storms over the Arabian sea: a case study. Nat Hazards 96:431-459. https://doi.org/10.1007/s1106 9-018-3550-2

15. Baldauf $M$, Seifert A, Forstner J, Majewski D, Raschendorfer $M$, Reinhardt T (2011) Operational convective-scale numerical weather prediction with the COSMO model: description and sensitivities. Mon Weather Rev 139(12):3887-3905. https://doi. org/10.1175/MWR-D-10-05013.1

16. Buzzi $M$ (2008) Challenges in operational numerical weather prediction at high resolution in complex terrain. $\mathrm{PhD}$ thesis, ETH Zurich, https://doi.org/10.3929/ethz-a-005698833

17. Steppeler J, Doms G, Schattler U, Bitzer HW, Gassmann A, Damrath U, Gregoric G (2003) Meso-gamma scale forecasts using the nonhydrostatic model LM. Meteorol Atmos Phys 82(1):75-96. https://doi.org/10.1007/s00703-001-0592-9

18. Anurose TJ, Subrahamanyam DB (2015) Evaluation of ABL parametrization schemes in the COSMO, a regional non-hydrostatic atmospheric model over an inhomogeneous environment. Model Earth Syst Environ 1(4):38. https://doi.org/10.1007/s4080 8-015-0045-y

19. Businger J, Wyngaard J, Izumi Y, Bradley E (1971) Flux-profile relationships in the atmospheric surface layer. J Atmos Sci 28:181-189

20. Louis J (1979) A parametric model of vertical eddy fluxes in the atmosphere. Bound Layer Meteorol 17:187-202

21. Anurose TJ, Subrahamanyam DB (2014) Assessment of a surfacelayer parameterization scheme in an atmospheric model for varying meteorological conditions. Ann Geophys 32(6):669-675. https://doi.org/10.5194/angeo-32-669-2014

22. Milelli M, Oberto E, Parodi A (2008) Sensitivity experiments of a severe rainfall event in North-Western Italy: 17 August 2006. Adv Sci Res 2:133-138

23. Ritter B, Geleyn JF (1992) A comprehensive radiation scheme for numerical weather prediction models with potential applications in climate simulations. Mon Weather Rev 120:303-325

24. Jacobsen I, Heise E (1982) A new economic method for the computation of the surface temperature in numerical models. Beitraege zur Physik der Atmosphaere 55:128-141

25. Heinze R, Dipankar A, Henken CC, Moseley C, Sourdeval O, Tromel S, Xie X, Adamidis P, Ament F, Baars H, Barthlott $\mathrm{C}$, Behrendt A, Blahak U, Bley S, Brdar S, Brueck M, Crewell S, Deneke H, Di Girolamo P, Evaristo R, Fischer J, Frank C, Friederichs $\mathrm{P}$, Gocke T, Gorges $K$, Hande L, Hanke M, Hansen A, Hege HC, Hoose C, Jahns T, Kalthoff N, Klocke D, Kneifel S, Knippertz $\mathrm{P}$, Kuhn A, van Laar T, Macke A, Maurer V, Mayer B, Meyer Cl, Muppa SK, Neggers RAJ, Orlandi E, Pantillon F, Pospichal B, Rober N, Scheck L, Seifert A, Seifert P, Senf F, Siligam P, Simmer C, Steinke S, Stevens B, Wapler K, Weniger M, Wulfmeyer V, Zangl G, Zhang D, Quaas J (2017) Large-eddy simulations over Germany using ICON: a comprehensive evaluation. Q J R Meteorol Soc 143(702):69-100. https://doi.org/10.1002/qj.2947

26. Schattler U, Doms G, Schraff C (2016) A description of the nonhydrostatic regional COSMO-model. DWD Report: User's Guide COSMO V 5.4:221

27. Zangl G, Reinert D, Rípodas P, Baldauf M (2015) The ICON (Icosahedral Non-hydrostatic) modelling framework of DWD and MPI-M: description of the non-hydrostatic dynamical core. $\mathrm{Q}$ J R Meteorol Soc 141(687):563-579. https://doi.org/10.1002/ qj.2378

28. Akkermans $T$, Bohme $T$, Demuzere $M$, Crewell $S$, Selbach C, Reinhardt T, Seifert A, Ament F, van Lipzig NPM (2012) 
Regime-dependent evaluation of accumulated precipitation in COSMO. Theor Appl Climatol 108:39-52. https://doi. org/10.1007/s00704-011-0502-0

29. Liu P, Want B, Sperber KR, Li T, Meehl GA (2005) MJO in the NCAR CAM2 with the Tiedtke convective scheme. J Clim 18:3007-3020

30. Tiedtke $M$ (1989) A comprehensive mass flux scheme for cumulus parameterization in large-scale models. Mon Weather Rev 117(8):1779-1800. https://doi.org/10.1175/15200493(1989)117<1779:ACMFSF>2.0.CO;2

31. Dee DP, Uppala SM, Simmons AJ, Berrisford $P$, Polia $P$, Kobayashi S, Andrae U, Balmaseda MA, Balsamo G, Bauer P, Bechtolda P, Beljaars ACM, van de Berg L, Bidlot J, Bormann N, Delsol C, Dragania R, Fuentes M, Geera AJ, Haimberger L, Healy SB, Hersbacha $\mathrm{H}$, Holm EV, Isaksen L, Kallberg $P$, Kohler M, Matricardi $M$, McNally AP, Monge-Sanz BM, Morcrette JJ, Park BK, Peubey C, de Rosnay P, Tavolato C, Thepaut JN, Vitart F (2011) The ERAinterim reanalysis: configuration and performance of the data assimilation system. Q J R Meteorol Soc 137:553-597. https:// doi.org/10.1002/qj.828

32. Meng X, Cheng J (2018) Evaluating eight global reanalysis products for atmospheric correction of thermal infrared sensor-application to Landsat 8 TIRS10 data. Remote Sens 10(3):474. https:// doi.org/10.3390/rs10030474

33. Huffman GJ, Bolvin DT, Nelkin EJ, Wolff DB (2007) The TRMM multisatellite precipitation analysis (TMPA): quasi-global, multiyear, combined-sensor precipitation estimates at fine scales. J Hydrometeorol 8(1):38-55. https://doi.org/10.1175/JHM560.1

34. Huffman GJ, Stocker EF, Bolvin DT, Nelkin EJ, Tan J (2019) GPM IMERG final precipitation L3 1 day 0.1 degree $\times 0.1$ degree $v 06$. Edited by Andrey Savtchenko, Greenbelt, MD, Goddard Earth Sciences Data and Information Services Center (GES DISC). https ://doi.org/10.5067/GPM/IMERGDF/DAY/06

35. Chavas D, Reed K, Knaff J (2017) Physical understanding of the tropical cyclone wind-pressure relationship. Nat Commun 8:1360. https://doi.org/10.1038/s41467-017-01546-9

36. Knaff JA, Zehr RM (2007) Reexamination of tropical cyclone wind-pressure relationships. Weather Forecast 22(1):71-88. https://doi.org/10.1175/WAF965.1

37. Champion AJ, Hodges K (2014) Importance of resolution and model configuration when downscaling extreme precipitation. Tellus A 66:23993. https://doi.org/10.3402/tellusa.v66.23993

Publisher's Note Springer Nature remains neutral with regard to jurisdictional claims in published maps and institutional affiliations. 